\title{
Cyclic response of insulated steel angle brackets used for cross-laminated timber connections
}

\author{
Meta Kržan ${ }^{1} \cdot$ Boris Azinović ${ }^{10}$
}

Received: 27 March 2020 / Accepted: 24 November 2020 / Published online: 10 January 2021

(c) The Author(s) 2021

\begin{abstract}
In cross-laminated timber (CLT) buildings, in order to reduce the disturbing transmission of sound over the flanking parts, special insulation layers are used between the CLT walls and slabs, together with insulated angle-bracket connections. However, the influence of such CLT connections and insulation layers on the seismic resistance of CLT structures has not yet been studied. In this paper, experimental investigation on CLT panels installed on insulation bedding and fastened to the CLT floor using an innovative, insulated, steel angle bracket, are presented. The novelty of the investigated angle-bracket connection is, in addition to the sound insulation, its resistance to both shear as well as uplift forces as it is intended to be used instead of traditional angle brackets and hold-down connections to simplify the construction. Therefore, monotonic and cyclic tests on the CLT wall-to-floor connections were performed in shear and tensile/compressive load direction. Specimens with and without insulation under the angle bracket and between the CLT panels were studied and compared. Tests of insulated specimens have proved that the insulation has a marginal influence on the load-bearing capacity; however, it significantly influences the stiffness characteristics. In general, the experiments have shown that the connection could also be used for seismic resistant CLT structures, although some minor improvements should be made.
\end{abstract}

\section{Introduction}

In recent years, several high-rise and complex apartment buildings have been built entirely or partly using timber load-bearing elements (Foster et al. 2016; Ramage et al. 2017). This has generally been achieved as a result of the development of cross-laminated timber (CLT) structures (Brandner et al. 2016). These structures have several advantages, such as sustainability, energy efficiency and fast erection.

While mid-rise CLT or hybrid CLT buildings are becoming more common in non-seismic regions, recently a huge progress has been achieved also in design and construction of mid-rise timber buildings in seismic areas (Pei et al. 2016; Izzi et al. 2018). Seismic design principles for timber (and CLT) structures in Europe are to be updated in the

Boris Azinović

boris.azinovic@zag.si

Meta Kržan

meta.krzan@zag.si

1 Section for Timber Structures, ZAG Ljubljana (Slovenian National Building and Civil Engineering Institute),

Ljubljana, Slovenia new coming version of Eurocode 8, expected to be released (Follesa et al. 2018). In the design of earthquake resistant CLT structures, ductile connections play a crucial role by ensuring deformation capacity and energy dissipation of the structural system, due to the brittle nature of CLT panels. In addition to the load-bearing capacity and ductility, the information on the connection stiffness also is important, in order to obtain realistic modal vibration periods of the buildings for seismic design (Fragiacomo et al. 2011).

Several experimental studies have been conducted to better understand the mechanical behaviour of CLT wall panels with traditional connections, i.e. angle brackets and hold-downs, under in-plane lateral loading; monotonic and cyclic shear tests of CLT wall panels (Dujić et al. 2004, 2006; Lauriola and Sandhaas 2006; Popovski et al. 2010; Okabe et al. 2012; Hummel et al. 2013; Gavrić et al. 2015a) and tests of CLT single connections (Tomasi and Sartori 2013; Schneider et al. 2014; Flatscher et al. 2015; Gavrić et al. 2015b; Benedetti et al. 2019). It was found that regular angle brackets perform better under shear than under tensile loads (Flatscher et al. 2015; Gavrić et al. 2015b). On the other hand, the hold-downs prove to have a high stiffness and strength in the tensile direction and very low stiffness and strength under shear actions (Benedetti et al. 2019). 
The reason for this kind of behaviour is the elongated shape of the connection, which is not able to transfer a significant shear force to the base, generating brittle failure with very low stiffness and strength. The shear tests of CLT wall panels confirmed that next to the characteristics of the connection (type, geometry and mechanical characteristics of connectors) also other parameters, such as position of connectors on the panel, the vertical load, boundary conditions, etc. influence the seismic response of CLT wall panels. The connectors are in dependence of these various parameters subjected to both shear and tensile/compression loading, when the wall panel is laterally loaded. Therefore, experimental tests and numerical modelling of the coupling effect (simultaneous shear and axial loading) on angle brackets and hold-downs were conducted (Pozza et al. 2017, 2018; Liu and Lam 2018, 2019; Liu et al. 2020). It was established that the coupling effect should not be neglected in the numerical models for the design. Recently, a new type of shear-tension angle-bracket connection with nails in the vertical flange and inclined, fully threaded screws in the horizontal flange of the bracket has been developed to improve mechanical properties in tension compared to the regular angle brackets without the inclined screws (D'Arenzo et al. 2018, 2019). Analytical tension-shear domain was determined through monotonic shear and tensile tests and through numerical studies also for these innovative shear-tension angle-bracket connections.

Due to their low weight, timber structures tend to have other problematic issues, such as poor sound insulation (Caniato et al. 2017) and unpleasant vibrations under serviceability loads (Reynolds et al. 2016). One of the possibilities to reduce the disturbing sound transmission over the flanking parts, which is becoming increasingly common in CLT structures, is to use special elastic acoustic layers between the CLT wall and the floor panels (Reichelt et al. 2016). Depending on the design of the floor assembly, elastic layers can be placed underneath the walls or both underneath and on top of the walls. The selection of a suitable elastic layer depends on the static loads to which the structural element and the insulation layer are subjected, and on its dynamic parameters to provide a good acoustic performance. Conventional connectors between the CLT panels either penetrate the elastic layer or create sound bridges by not being isolated themselves and consequently reduce the acoustic performance of the structure.

For this reason, special angle brackets have been developed, where the rigid parts are elastically separated from each other to prevent sound transmission (Säly et al. 2008; Pitzl and Getzner 2018). However, besides the insulation, these connectors were, similar to the connector presented in D'Arenzo et al. (2018), specially designed to ensure good mechanical performance during an earthquake under both shear and axial loads and to simplify the connections between the CLT wall and floor panels. The strength and stiffness of this innovative angle bracket in the shear and tensile directions have been achieved with the use of inclined self-tapping screws to connect the angle brackets to the floor panel and also with a thick metal plate placed over the horizontal flange of the angle bracket (Fig. 1).

There were two main objectives of the presented research; first to evaluate the structural performance of the CLT connection with the presented innovative angle brackets (Pitzl and Getzner 2018) under shear and tensile/compression loading, and second, to evaluate the influence of the different types of sound insulation layers placed between the CLT panels and under the bracket, on the seismic performance

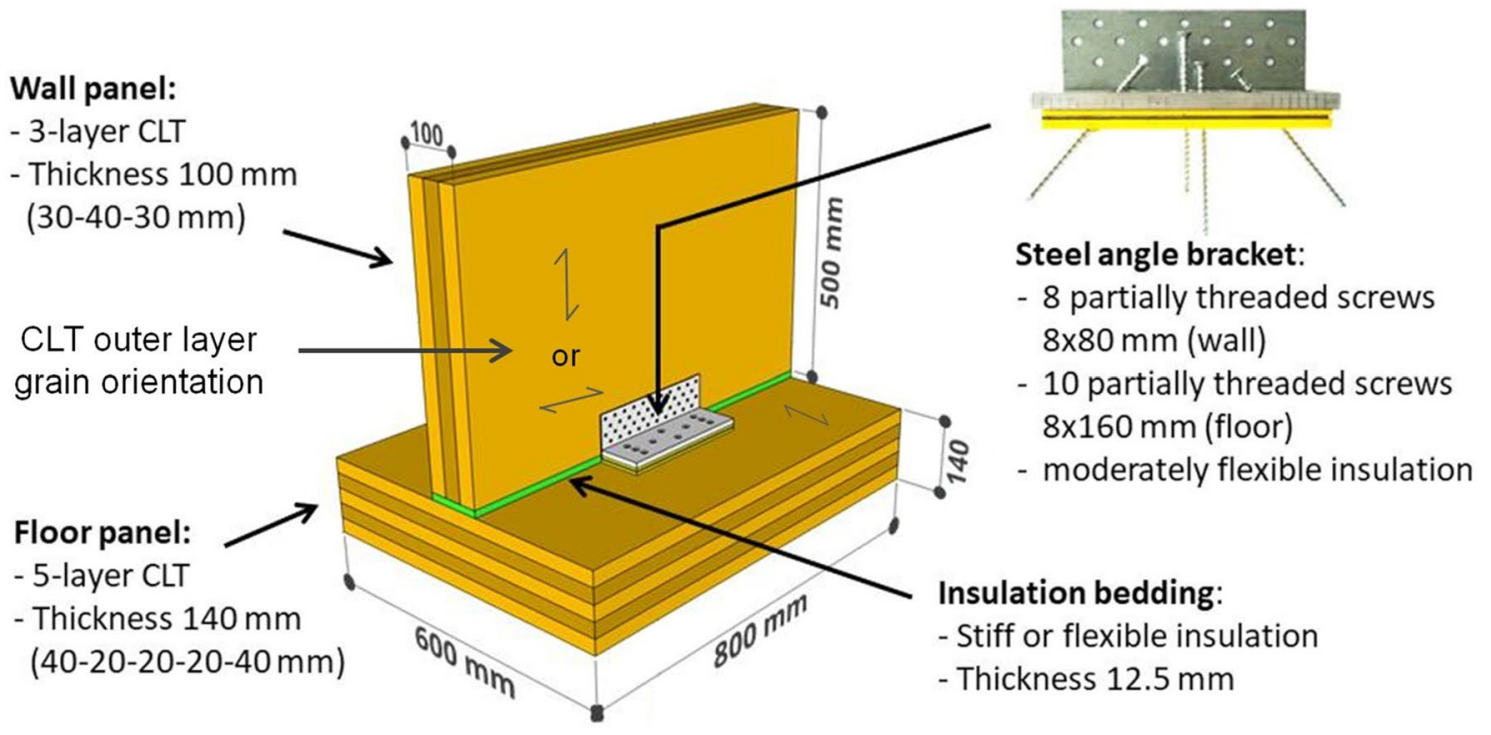

Fig. 1 Analysed test specimen (CLT wall and floor connected with insulated steel angle bracket with insulation bedding under the wall) 
of the connection. Except for two tests on CLT panels conducted by Hummel et al. (2013), no studies of seismic performance of CLT panels or connections with sound insulation layers between panels have yet been published.

For determining the behaviour of the investigated insulated CLT wall and floor panel connection with presented angle brackets under earthquake loads, an experimental campaign including monotonic and cyclic tests on single connections was conducted, where the surrounding CLT panels were reduced in size to simplify the experiment (Fig. 1). The used angle bracket is intended to serve both as a conventional angle bracket to prevent shear sliding, and to prevent uplift (instead of traditional hold downs). To generate the boundary conditions most similar to the actual use, besides the pure shear response of the connections also the influence of the vertical compressive load on the shear response was investigated. Furthermore, the same connection was analysed under tensile/compressive loads. To investigate the influence of the developed sound reduction details on the seismic behaviour of the structural system, the CLT wall and the floor panel connection were tested with and without insulation layer under the angle bracket and between the CLT panels. The results were evaluated in terms of stiffness, load-bearing capacity, displacement at failure and the nonlinear parameters characterizing the hysteresis behaviour (hysteretic damping, energy dissipation, etc.).

\section{Materials and methods}

\subsection{Test specimens and material characterization}

Test specimens representing the CLT wall and floor panel connected with a steel angle bracket were constructed with three-layer CLT panels of 100-mm thickness (40-30-40) for the wall and with five-layer CLT panels of 140-mm thickness (40-20-20-20-40) for the floor; CLT without narrow side bonding was used (ETA 12-0347 (OIB 2017)). The goal of the testing program was to obtain results of cyclic behaviour for general use of the insulated angle brackets. To take into account all possible applications of the angle brackets, the specimens had both orientations of the outer layers of the CLT plates for the wall panels; the outer laminations orthogonal to the CLT slab (most common orientation in case of CLT walls) as well as parallel to the slab (possible use for CLT deep beams, CLT cantilevers, vertical connection between CLT walls, special architectural demands). It is assumed, however, that for the CLT and connection used in the study, the grain orientation of the outer layers should not significantly influence the stiffness and load-bearing capacity. As observed in previous investigations, for CLT with standard layer thicknesses ( $\mathrm{t}>9 \mathrm{~mm})$, the embedment strength of laterally loaded self-tapping screws in the CLT side face $\left(d_{\mathrm{sc}} \leq 8 \mathrm{~mm}, d_{s c}=\right.$ screw diameter), could be estimated in the same way as for solid wood, regardless of the grain orientation in the outer layer (Ringhofer et al. 2018).

Angle bracket of size $100 \times 100 \times 240 \times 3 \mathrm{~mm}$ (steel S250GD + Z275) and an additional 14-mm-thick metal plate (Aluminium EN AW 6082) over the horizontal leg were fastened to a wall panel with 8 partially threaded screws $8 \times 80 \mathrm{~mm}$ (ETA 12/0276 (DIBt 2017)) and to the floor with 10 partially threaded screws $8 \times 160 \mathrm{~mm}$ (ETA 12/0276 (DIBt 2017)). For the later, four screws were installed vertically in the central part of the steel plate and three were installed next to them on each side at an angle of $45^{\circ}$ (Fig. 1). The configuration (number and geometry) of the screws for fastening the horizontal and vertical flange to CLT elements was as recommended by the manufacturer of the insulated angle brackets on the basis of preliminary tests.

To study the influence of the insulation material on the seismic response, two groups of insulation bedding material between the CLT elements differing in the elastic properties of the material and in the insulation static load limit were tested (see Table 1); a stiffer insulation with a static load limit up to 1.5 MPa (labelled as "Stiff.ins.", used in structures for a higher static loading) and a moderately flexible one with a static load limit of approximately $0.05 \mathrm{MPa}$ (labelled as "Flex.ins.", used for lower static loading, e.g., in the highest floors of the structures). For each group, specimens with a mixed cellular polyurethane ("MCP") sheet (Getzner GmbH 2019a) and a closed cellular polyurethane ("CCP") sheet (Getzner GmbH 2019b) were tested. Despite

Table 1 Testing program

\begin{tabular}{llll}
\hline Insulation & Shear test (no vertical load) & $\begin{array}{l}\text { Shear test with } \\
\text { vertical load }\end{array}$ & Tension/(compression) test \\
\hline None ("Unins.") & 2 monotonic (Ms), & 1 cyclic (Cs-v) & 1 monotonic (Mt), \\
& 2 cyclic (Cs) & & 1 cyclic (Ct) \\
Stiff insulation ("Stiff.ins.") & 2 monotonic (Ms), & 2 cyclic (Cs-v) 1 monotonic (Mt), \\
& 4 cyclic (Cs) & & 2 cyclic (Ct) \\
Flexible insulation (“Flex.ins.”) & 2 monotonic (Ms), & $/$ & \\
& 4 cyclic (Cs) & & \\
\hline
\end{tabular}

$M s$ monotonic shear test, $C s$ cyclic shear test, $C s-v$ cyclic shear test with vertical load, $M t$ monotonic tension test, $C t$ cyclic tension/compression test 
their different influence on sound protection (mixed cellular elastomers are characterized by highly elastic behaviour, while closed cellular elastomers provide more damping), similar mechanical response to static and low-cycle dynamic loading was expected. The insulation bedding of thickness $12.5 \mathrm{~mm}$ was laid under the wall (Fig. 1). For all the specimens with insulation bedding between the CLT panels, the angle brackets were identically insulated with two layers of moderately flexible closed cellular polyurethane (Getzner $\mathrm{GmbH} 2019 b$ ) with a total thickness of $12.5 \mathrm{~mm}$ (Fig. 1).

\subsection{Testing program}

The testing program (Table 1) consisted of 18 shear tests varying in terms of the presence and type of insulation (stiff, flexible), orientation of the CLT wall's outer layers and in the application of vertical load (no vertical loading vs. coupled shear and vertical loading) and of 7 preliminary tension/compression tests varying in terms of the presence and type of insulation. For the tensile tests, all the test specimens had grain orientation of the outer laminations of the CLT walls parallel to the CLT slab, i.e. orthogonal to tensile loading. To define the loading protocol, monotonic tests were conducted prior to the cyclic tests.

For the shear tests, the loading was applied to the wall panel $150 \mathrm{~mm}$ above the floor panel and the out-of-plane displacements of the specimens were restrained by a steel element with a PTFE layer to eliminate friction at the top of the wall panel (Fig. 2a). For the tension/compression tests, the steel element served to fix the specimen and to introduce the tensile/compressive loading (Fig. 2b). A servo-hydraulic actuator of capacity $160 \mathrm{kN}$ was used for all the tests. For the coupled shear and compression tests, the vertical load was chosen with regard to the insulation static range of use and was induced by pre-compression. Due to the low static load range of flexible insulation, only stiff insulation was used in coupled shear/compression tests. Prior to the start of the test, a vertical load of $100 \mathrm{kN}$ (corresponding to normal stress
1.42 MPa under the CLT wall panel) was applied by straining the steel tendons as a result of fastening the steel nuts. The vertical load was during the test, however, reduced due to minimal rocking of the specimen, which caused loosening of the nuts. This deficiency of the test setup was controlled by measuring the actual force at the centre of the wall specimens with a load cell. Relative displacements between the wall and the floor panel were measured with four 100$\mathrm{mm}$ or $200-\mathrm{mm}$ linear variable displacement transformers (tolerance $\leq 0.1 \mathrm{~mm}$ or $0.2 \mathrm{~mm}$, respectively), positioned at the ends of the wall on both sides (Fig. 2). The relative displacements used for analysing the results are calculated as average values of all four recorded values for both shear and tension tests.

In all the tests the loading was induced by controlling the increase in the lateral displacement (approximate rate $0.2 \mathrm{~mm} / \mathrm{s}$ ) except in the cyclic tension/compression tests, where the loading in compression was, from a certain displacement onwards, limited by the maximum actuator capacity. The loading protocol for cyclic tests was defined according to ISO 16670 (2003) and therefore based on the results of the ultimate displacement capacity obtained in monotonic tests (i.e., displacement $d_{\mathrm{u}}$, where the post-peak load resistance decreased to $80 \%$ of the load-bearing capacity). As seen in Table 1, monotonic shear tests were performed for the uninsulated specimens and for specimens with both types of insulation. For cyclic tests, a uniform loading protocol was adopted for all specimens on the basis of average $d_{\mathrm{u}}$ of all monotonic tests. In the case of the tension/compression tests, it was assumed that the type of insulation has no influence on the response of the connection under tensile loads. For this reason only two monotonic tension tests were performed: one on an uninsulated specimen and one on an insulated specimen.

For cyclic tests, the loading was induced in cycles by subsequently increasing the displacement amplitudes in both directions from the initial position. After the first five initial displacement amplitude cycles, the following loading
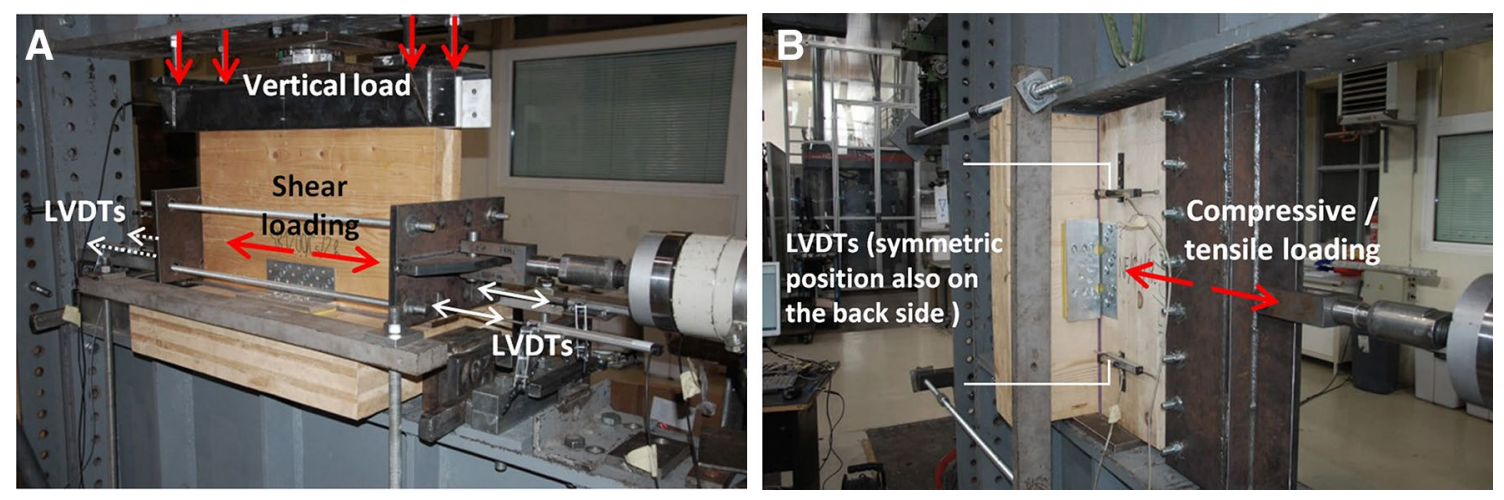

Fig. 2 a Shear test setup (coupled vertical and shear loading); b tension/compression test 
protocol consisted of three cycles to obtain the strength and stiffness degradation. The increase in the amplitude displacements was determined according to ISO 16670 as a certain part of the average ultimate displacement $\left(d_{\mathrm{u}}\right)$, achieved during monotonic tests $(80 \mathrm{~mm}) ; 20 \%$ of the $d_{\mathrm{u}}$ increase $(16 \mathrm{~mm})$ for amplitude displacements higher than $20 \%$ of $d_{\mathrm{u}}$ was prescribed.

\section{Results and discussion}

\subsection{Shear response}

When comparing the specimens for the same type of shear test between each other, the differences in terms of the damage mechanism were marginal. Similar damage mechanisms were also obtained when comparing the specimens with orthogonal and parallel outer layers orientation of the CLT wall, where some minor differences were present in the amount of wood crushing in the outer laminations. Typical damage observed in the shear experiments can be summarized as follows: damage to the wood around the screws due to wood crushing (Fig. 3a), embedment (Fig. 3b, c) and withdrawal of the screws from the wall panel (Fig. 3a) or, in fewer cases, from the floor panel (Fig. 3b). Plastic deformations of the screws were attained in all tests (Fig. 3d). For the tests with coupled shear and compressive loading, shear failure of the screws in the wall panel (Fig. 3c) occurred in all the tests, while this failure mechanism was not common when no vertical load was applied. Plastic deformations in the steel part of the angle bracket were present in all the tests (Fig. 3e) but were more apparent in tests with no vertical load on the insulated specimens (Fig. 3b). This is reasonable, since the rocking mechanism was more expressed in the case of the insulated specimens due to the deformable insulation bedding under the CLT panel and the insulation under the angle bracket.

In Fig. 4, typical responses in terms of hysteresis curves of lateral force vs. displacement obtained for uninsulated and insulated specimens under cyclic shear loading and coupled shear and vertical loading are presented. Since the vertical loading was not constant throughout the coupled shear and vertical loading tests, in Fig. 5, time history diagrams of the measured compression force $F_{\text {ver }}$ and the obtained shear resistance $F_{\text {hor }}$ are presented for the two tests together with the average measured lateral displacements. Additionally, in Fig. 6a, a comparison of the backbone hysteresis envelopes is shown, whereas in Fig. $6 \mathrm{~b}$ results of cyclic tests with no vertical loading are compared to results of monotonic shear tests.

The seismic performance of the investigated specimens under shear loading was analysed in terms of the load-bearing $\left(F_{\max }\right)$ and displacement (deformation) capacity $\left(d_{\mathrm{u}}\right)$. For a more comprehensive comparison, the force-displacements curves were idealized to bi-linear curves in order to compare the ductility ( $\mu$, defined as the ultimate displacement to yield displacement $d_{\mathrm{y}}$ ), idealized load-bearing capacity $F_{\text {id }}$ and effective stiffness $K_{\text {ef. }}$. The Yasumura and Kawai (1998) and Kobayashi and Yasumura (2011) idealisation criteria were considered for the idealisation, since as opposed to EN 12512 (2002), the equivalent energy criterion is assumed to obtain the $d_{\mathrm{y}}$ value of the elastic-plastic curve. The effective stiffness $K_{\text {ef }}$ (ratio of $d_{\mathrm{y}}$ to $F_{\text {id }}$ ) is defined through the intersection of the two secant stiffnesses $K_{0.1-0.4}$ and $K_{0.4-0.9}$, obtained for the displacements corresponding to $0.1,0.4$ and $0.9 F_{\max }$. The intersection of $K_{0.1-0.4}$ and $K_{0.4-0.9}$, the latter positioned to be at a tangent on the obtained curve, defines the load at which the $K_{\text {ef }}$ should be evaluated on the curve (see Fig. 7). With $K_{\text {ef }}$ known, $d_{\mathrm{y}}$ is calculated by assuming the equal energy input of the hysteresis envelope and the bi-linear diagram up to $d_{\mathrm{u}}$. Since for structural analyses and design under serviceability loads the elastic stiffness represents an important value, the average $K_{0.1-0.4}$ values are also provided in Table 2.

The cyclic shear test results, presented in Table 2, consider the average results of tests for both directions of loading. For insulated specimens, the average results are for both monotonic and cyclic tests presented considering each type of insulation separately. No significant or systematic difference in capacity or other nonlinear response characteristics were found for specimens with orthogonal and parallel orientation of the outer lamination in the CLT wall, therefore average results of all specimens are presented.

\subsubsection{Influence of insulation}

The insulation bedding between the CLT panels and under the angle bracket did not have a significant influence on the shear load-bearing and displacement capacity of the system. In cases when no vertical load was applied, a less than 5\% decrease of $F_{\text {id }}$ and a 7\% increase of $d_{\mathrm{u}}$ were obtained for the insulated specimens in comparison with the uninsulated specimens in the cyclic tests (Table 3). However, the insulation reduced the stiffness of the analysed CLT connection. A reduction of over $20 \%$ was established for $K_{\text {ef }}$ and $K_{0.1-0.4}$ (Table 3) with a considerably large reduction in stiffness identified for small displacements, which can be seen from the comparisons of the backbone curves in Fig. 6. For example, the average secant stiffness at $2 \mathrm{~mm}$ was in cyclic tests for the insulated specimens smaller for approximately $65 \%$ in comparison to the uninsulated specimens. This effect can to some extent be attributed to the shear as well as the vertical deformability of the insulation bedding. Since the insulation bedding presents a more deformable support than in the case of a direct timber-to-timber connection, larger rocking of the CLT wall panel was obtained for the smaller 

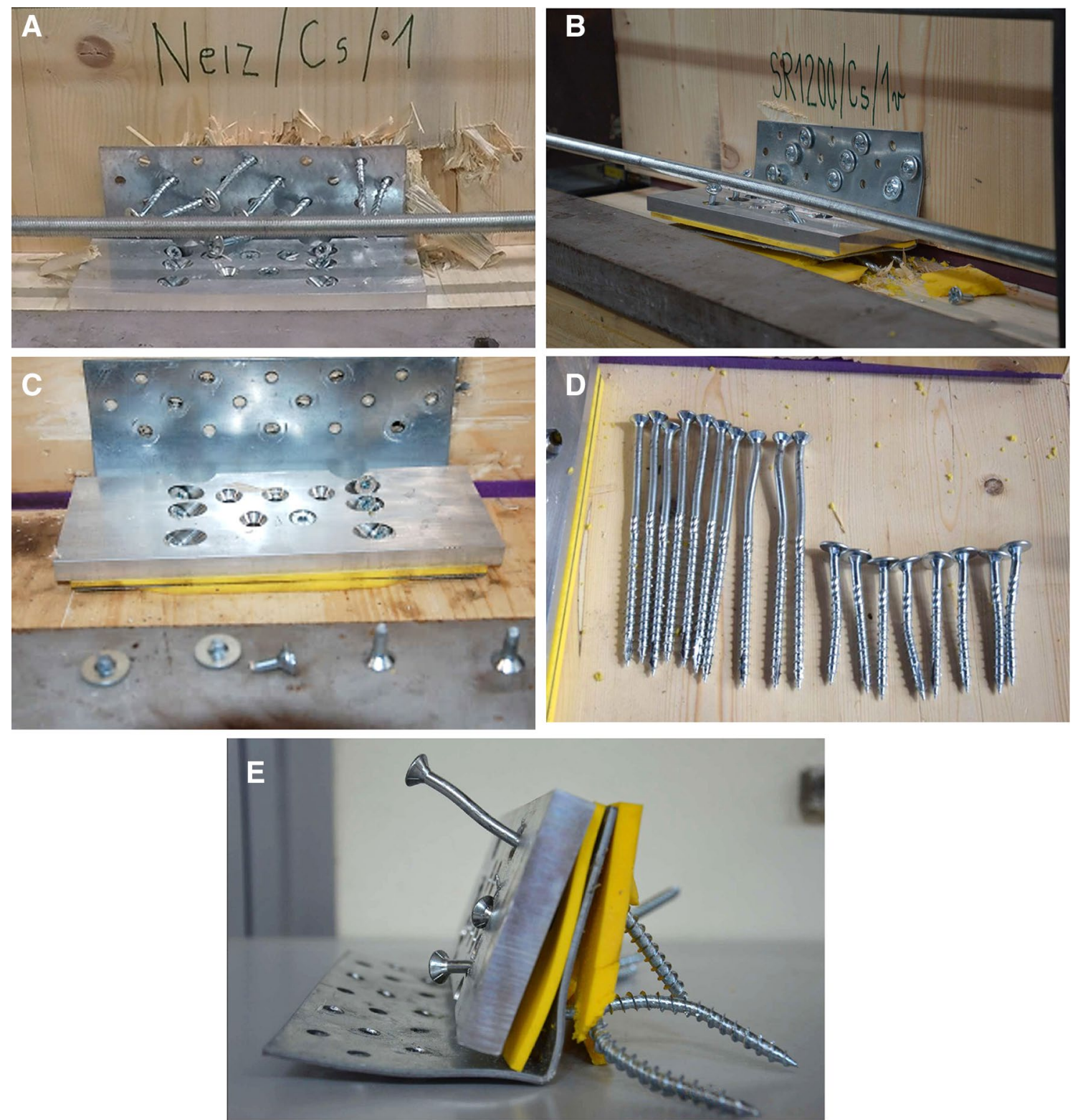

Fig. 3 Damage to the specimens in shear tests: a wood damage and withdrawal of the screws in the wall panel; $\mathbf{b}$ embedment and withdrawal of the screws in the floor panel and plastic deformations of the steel angle

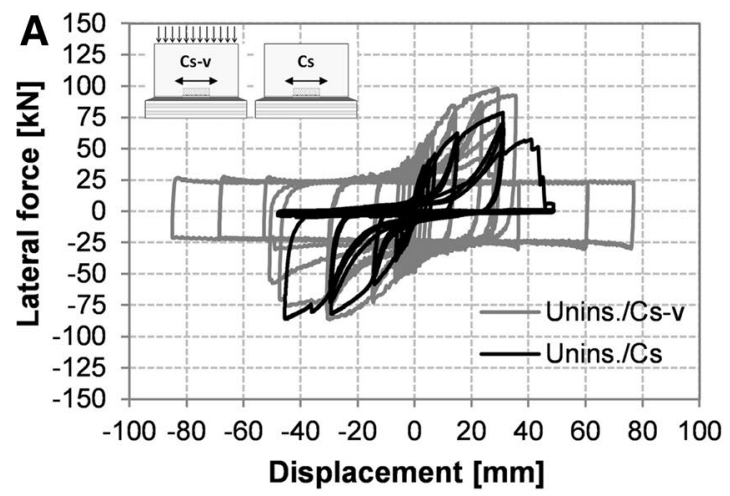

bracket; $\mathbf{c}$ embedment and shear failure of the screws in the wall panel; $\mathbf{d}$ plastic deformations of the screws (after monotonic test); e plastic deformations of the angle bracket (insulated specimen after cyclic shear test)

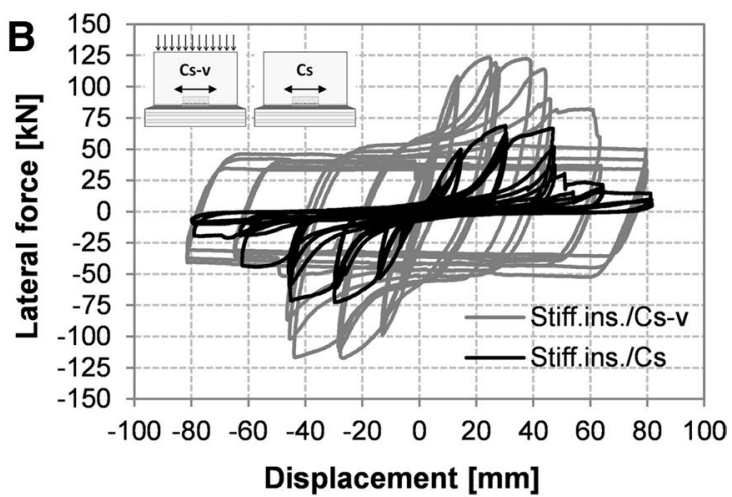

Fig. 4 Typical hysteresis curves obtained in cyclic shear (Cs) and coupled shear and vertical loading (Cs-v) tests: a for uninsulated specimens (Unins.); $\mathbf{b}$ for specimens with stiff insulation (Stiff.ins.) 

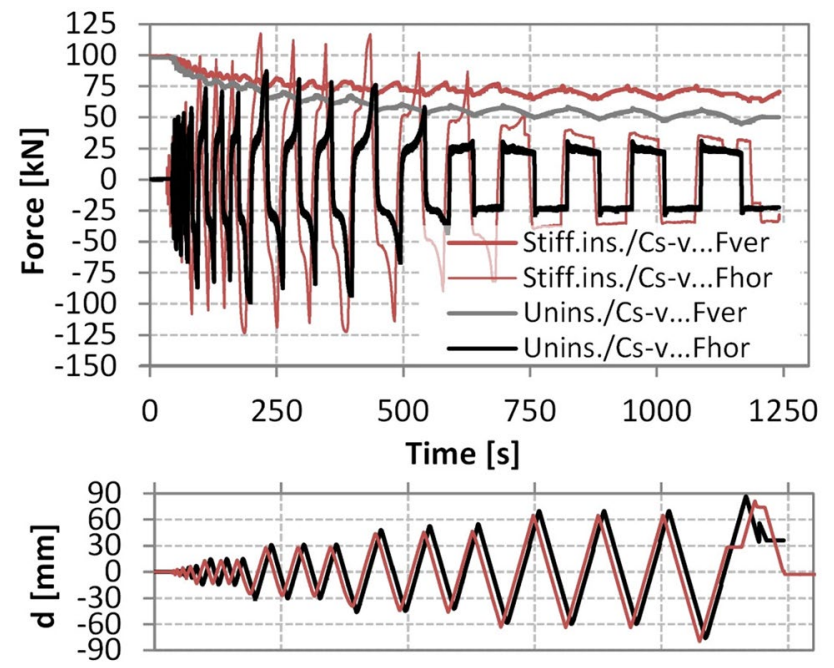

Fig. 5 Recorded time history of the obtained shear resistances $\left(\mathrm{F}_{\text {hor }}\right)$, corresponding vertical loading $\left(\mathrm{F}_{\mathrm{ver}}\right)$ and average measured displacement $(d)$ for the insulated (Stiff.ins./Cs-v) and uninsulated (Unins./ Cs-v) specimens

lateral displacements in the case of the insulated specimens. The compressive and shear deformations of the insulation therefore cause a smaller overall shear resistance of the connection for a smaller displacement, since the governing mechanism of transferring the shear force to the CLT floor is through the insulation and not the embedment of the screws in the wood.

Another reason for reduction in shear stiffness for the insulated specimens is due to the interlayers, generated by the insertion of the insulation between the thick metal plate and angle bracket as well as insulation underneath the angle bracket. This phenomenon was also observed in other studies of timber connections with dowel-type fasteners. The influence of interlayers on strength and stiffness has been previously discovered for timber concrete composites, where the interlayer is used to simulate formwork. Gelfi et al. (2002) used the beam on elastic foundation model to validate experimental data, where the interlayer was modelled as a void space with a variable thickness. It was found that the connection stiffness significantly depends on the values of the embedded lengths both in the concrete and in the wood. The stiffness of the connection is reduced when the thickness of the interlayer increases. Similarly, Dias et al. (2010) also concluded that the use of a $20 \mathrm{~mm}$ thick interlayer between timber and concrete reduced the slip modulus of the dowel-type joint by around $35 \%$. Future work is necessary in this field to distinguish between the reduction in connections' shear stiffness due to the insertion of insulation bedding between CLT panels and due to the use of insulated angle bracket.

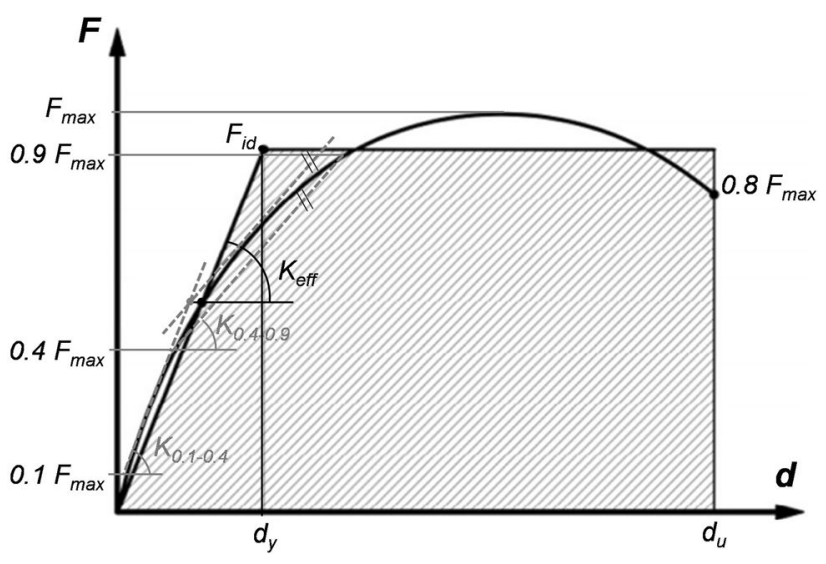

Fig. 7 Determination of bi-linear force - displacement curve according to Yasumura and Kawai (1998) and Kobayashi and Yasumura (2011)

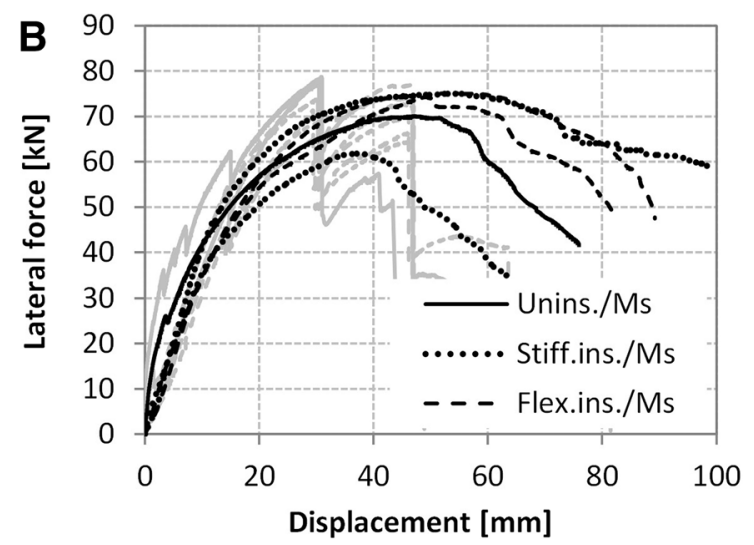

and flexible (Flex.ins.) insulation bedding; b the hysteresis backbone curves for one loading direction for cyclic shear and results of monotonic shear tests.
Fig. 6 Comparison of a the hysteresis backbone curves for cyclic shear (Cs) and coupled shear and vertical loading (Cs-v) tests for uninsulated specimens (Unins.) and specimens with stiff (Stiff.ins.) 
Table 2 Average results of shear load-bearing capacity, displacement capacity and stiffness for monotonic and cyclic shear tests

\begin{tabular}{|c|c|c|c|c|c|c|c|}
\hline Insulation/test (no. of specimens) & $\begin{array}{l}F_{\max }(\mathrm{CoV}) \\
{[\mathrm{kN}]}\end{array}$ & $\Delta F_{\max , 1-3} / F_{\max , 1}[/]$ & $\begin{array}{l}F_{\text {id }}(\mathrm{CoV}) \\
{[\mathrm{kN}]}\end{array}$ & $\begin{array}{l}d_{\mathrm{u}}(\mathrm{CoV}) \\
{[\mathrm{mm}]}\end{array}$ & $\begin{array}{l}\mu(\mathrm{CoV}) \\
{[/]}\end{array}$ & $\begin{array}{l}K_{\mathrm{ef}}(\mathrm{CoV}) \\
{[\mathrm{kN} / \mathrm{mm}]}\end{array}$ & $\begin{array}{l}K_{0.1-0.4}(\mathrm{CoV}) \\
{[\mathrm{kN} / \mathrm{mm}]}\end{array}$ \\
\hline Unins./Ms (2 tests) & $68.1(3.9 \%)$ & & $61.9(5.1 \%)$ & $51.9(31.8 \%)$ & $3.68(32.5 \%)$ & $4.38(5.8 \%)$ & $4.18(18.1 \%)$ \\
\hline Stiff.ins./Ms (2 tests) & $68.4(13.6 \%)$ & & $62.1(14.1 \%)$ & $72.5(45.2 \%)$ & $4.37(41.4 \%)$ & $3.77(9.7 \%)$ & $4.12(19.8 \%)$ \\
\hline Flex.ins./Ms (2 tests) & $74.8(0.5 \%)$ & & $68.4(0.8 \%)$ & $78.4(9.1 \%)$ & $3.68(4.7 \%)$ & $3.21(3.7 \%)$ & $3.71(8.1 \%)$ \\
\hline Unins./Cs (2 tests) & $79.6(4.8 \%)$ & $40.6 \%$ & $70.7(3.8 \%)$ & $43.1(11.7 \%)$ & $2.87(39.1 \%)$ & $4.79(46.8 \%)$ & $5.05(58.8 \%)$ \\
\hline Stiff.ins./Cs (4 tests) & $77.6(6.1 \%)$ & $23.0 \%$ & $68.7(3.9 \%)$ & $46.4(0.5 \%)$ & $2.64(6.7 \%)$ & $3.90(9.6 \%)$ & $4.33(6.1 \%)$ \\
\hline Flex.ins./Cs (4 tests) & $71.8(4.6 \%)$ & $19.7 \%$ & $66.6(5.0 \%)$ & $45.9(0.4 \%)$ & $2.51(6.3 \%)$ & $3.59(11.7 \%)$ & $3.68(3.3 \%)$ \\
\hline Unins./Cs-v (1 test) & 92.3 & $32.9 \%$ & 76.3 & 41.6 & 26.7 & 44.0 & 42.3 \\
\hline Stiff.ins./Cs-v (2 tests) & $123.7(3.6 \%)$ & $6.7 \%$ & $114.3(1.8 \%)$ & $45.3(1.1 \%)$ & $5.46(43.0 \%)$ & $13.8(43.6 \%)$ & $14.9(50.7 \%)$ \\
\hline
\end{tabular}

$F_{\max }$ shear load-bearing capacity, $\Delta F_{\max , 1-3} / F_{\text {max }, 1}$ strength degradation in 3rd cycle compared to 1 st cycle for amplitude displacements, at which maximum resistance was obtained, $F_{\text {id }}$ idealized shear load-bearing capacity, $d_{\mathrm{u}}$ ultimate displacement (at $80 \%$ of post-peak load-bearing capacity), $\mu$ ductility, $K_{\text {ef }}$ effective stiffness (stiffness of the bi-linear curve), $K_{0.1-0.4}$ elastic stiffness (secant stiffness at 0.1 and $0.4 F_{\text {max }}$ ), labels Unins., Stiff.ins. and Flex.ins. stand for uninsulated specimens, specimens with stiff and with flexible insulation bedding, respectively. Labels Ms, Cs and Cs-v stand for monotonic shear, cyclic shear and cyclic shear test with vertical load

Table 3 Influence of insulation, vertical load and loading protocol on the results

\begin{tabular}{llllllll}
\hline Tests & Comparison (ratio) & \multicolumn{2}{l}{ Parameter } \\
\cline { 3 - 8 } & & $F_{\text {id }}$ & $d_{\mathrm{y}}$ & $d_{\mathrm{u}}$ & $\mu$ & $K_{\mathrm{ef}}$ & $K_{0.1-0.4}$ \\
\hline Ms: & Insulated/uninsulated & 1.05 & 1.34 & 1.45 & 1.09 & 0.80 & 0.94 \\
Cs: & Insulated/uninsulated & 0.96 & 1.08 & 1.07 & 0.90 & 0.78 & 0.79 \\
Cs-v: & Insulated/uninsulated & 1.50 & 5.85 & 1.09 & 0.20 & 0.31 & 0.35 \\
Uninsulated: & $\mathrm{Cs} / \mathrm{Ms}$ & 1.14 & 1.18 & 0.83 & 0.78 & 1.09 & 1.21 \\
Insulated: & $\mathrm{Cs} / \mathrm{Ms}$ & 1.04 & 0.95 & 0.61 & 0.64 & 1.07 & 1.02 \\
Uninsulated: & $\mathrm{Cs-v/Cs}$ & 1.08 & 0.09 & 0.97 & 9.30 & 9.20 & 8.37 \\
Insulated: & $\mathrm{Cs}-\mathrm{v} / \mathrm{Cs}$ & 1.69 & 0.51 & 0.98 & 2.12 & 3.68 & 3.73 \\
\hline
\end{tabular}

Average results of 2 tests are considered for monotonic (Ms) and cyclic (Cs) tests for the uninsulated specimens and average results of all the specimens with insulation for results of the insulated specimens (4 tests for monotonic shear tests (Ms), 8 tests for cyclic shear test (Cs), 2 tests for cyclic coupled shear and vertical loading tests (Cs-v))
The insertion of insulation could cause a reduction in ductility compared to the uninsulated connections. For the cyclic tests, on average a $10 \%$ decrease in ductility was obtained for the insulated specimens due to their considerably lower average effective stiffness, but only moderately higher ultimate displacement capacity.

\subsubsection{Influence of vertical load and loading protocol}

The results of the tests confirm the positive influence of the vertical load on the shear load-bearing capacity due to frictional forces (Table 3). The shear resistance provided by friction is similar for insulated and uninsulated specimens. The coefficient of friction was evaluated for each specimen after the ultimate displacement capacity $\left(d_{\mathrm{u}}\right)$ and failure of the connection had been reached considering the actually measured vertical forces; coefficients of friction equal to 0.54 and 0.57 were obtained for the uninsulated specimens and specimens with stiff insulation, respectively.
For an uninsulated specimen, the total shear load-bearing capacity, in the case of an applied vertical load, increased by $8 \%$. Due to the frictional forces between the CLT panels activated from the beginning of the test, there was a significant increase in the elastic and effective stiffnesses $\left(K_{\text {ef }}\right.$ more than nine-times higher compared to the tests without a vertical load). Consequently, the ductility was also higher, since the displacement capacity was neither for uninsulated nor for insulated specimens affected by the introduction of a vertical load.

A more substantial increase in the load-bearing capacity in the case of coupled shear and vertical loads was, however, achieved for the insulated specimens; the total shear strength capacity increased for on average $69 \%$. The results confirm that the response of the connection can significantly be altered by the presence of the vertical load. Because of various influencing mechanisms (friction, rocking, compression of the CLT slab perpendicular to grain), the contribution of each component to the total load-bearing capacity 
is not straightforward. For analysing the differences in the nonlinear stages of the response, further studies are needed. In the present study, only the hypothesis that the total loadbearing capacity is increased could be confirmed.

Due to the frictional forces between the CLT panels, there was however a significant increase in the elastic and effective stiffnesses ( $K_{\text {ef }}$ more than nine-times higher compared to the tests without a vertical load). Consequently, the ductility also was higher, since the displacement capacity was neither for uninsulated nor for insulated specimens affected by the introduction of vertical load. A significantly smaller stiffness increase was obtained in the case of the insulated specimens in comparison to the uninsulated specimen when the vertical load was applied. Besides the relatively large dispersion of results and the influence of idealization criteria, the smaller stiffness increase can be explained by the additional elastic shear and vertical deformation of the insulation.

With the high decrease in stiffness obtained with the insertion of insulation for shear response under vertical loading a very large reduction in ductility was also obtained. For the induced vertical loading, the insulated specimens reached only $20 \%$ of the ductility of the uninsulated specimens, while reaching similar ultimate displacements.

The comparison of shear test results for both uninsulated and insulated specimens in dependence of the loading protocol shows that while a small increase in the load-bearing capacity may be expected in case of cyclic loading, displacement capacity can significantly be reduced. This implies that in order to assess the deformation capacity and the ductility of the connection in a way to ensure safe seismic design, not only monotonic but also cyclic tests should be conducted.

\subsection{Tensile response}

The withdrawal of the screws from the floor panel and the large deformations of the angle bracket (Fig. 8a) were evident in all the tension/compression tests. The withdrawal was critical in three tests (Unins./Mt, Ins./Mt and Ins./ $\mathrm{Ct}$ ), while in two tests, block shear failure in the CLT wall (Fig. 8b) and in two cases, net tensile failure of the CLT wall panel (outer lamination, Fig. 8c) occurred. Since block shear and net tensile failure modes of the wall panel presented in Fig. 8b, c are a result of tension perpendicular to grain loading of the outer layer due to the horizontal orientation of the outer layers of the CLT wall panel (orthogonal to tensile loading), these modes may not have occurred if the CLT wall panel's orientation had been in the vertical direction as it usually is in wall elements in CLT buildings. However, to confirm this, additional tests would be needed. In reality, such small width of the CLT panel also is rare. Nevertheless, the results show, that the connection should be improved for use in seismic areas to prevent brittle failures of the CLT, for example, by increasing the end distance of the screws in the CLT wall.

In Fig. 9, tensile force vs. displacement curves for monotonic and cyclic tension/compression tests (hysteresis envelope curves for the tensile part) are presented, whereas in Table 4 results of each test are summarized
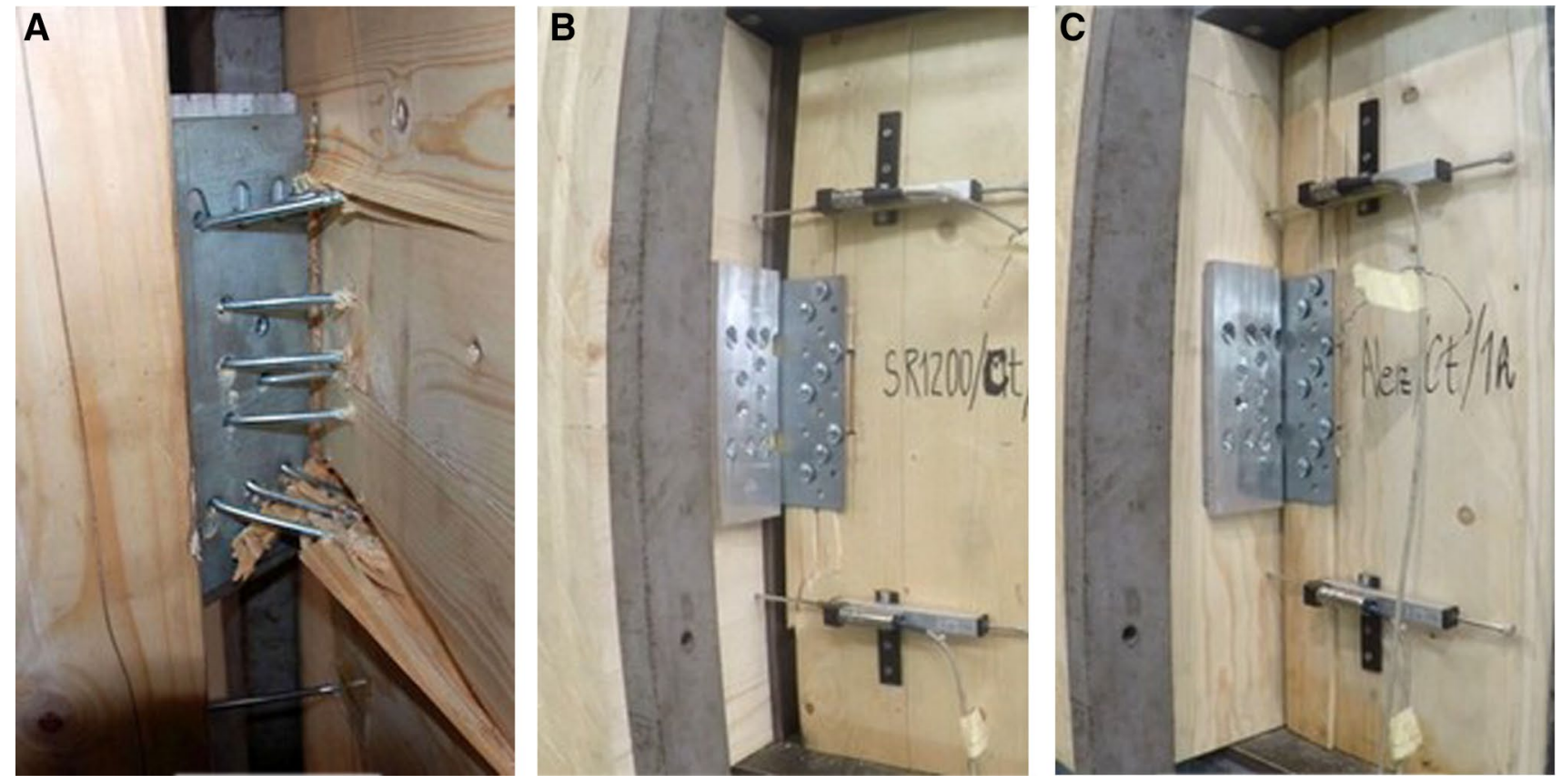

Fig. 8 Damage at failure in tension/compression tests: a withdrawal of the screws from the floor panel (back view of the specimen); b block shear failure in the CLT wall panel; $\mathbf{c}$ net tensile failure of the CLT wall 
Fig. 9 Comparison of the hysteresis envelopes of the tensile part of cyclic tension/compression tests and the results of monotonic tension tests

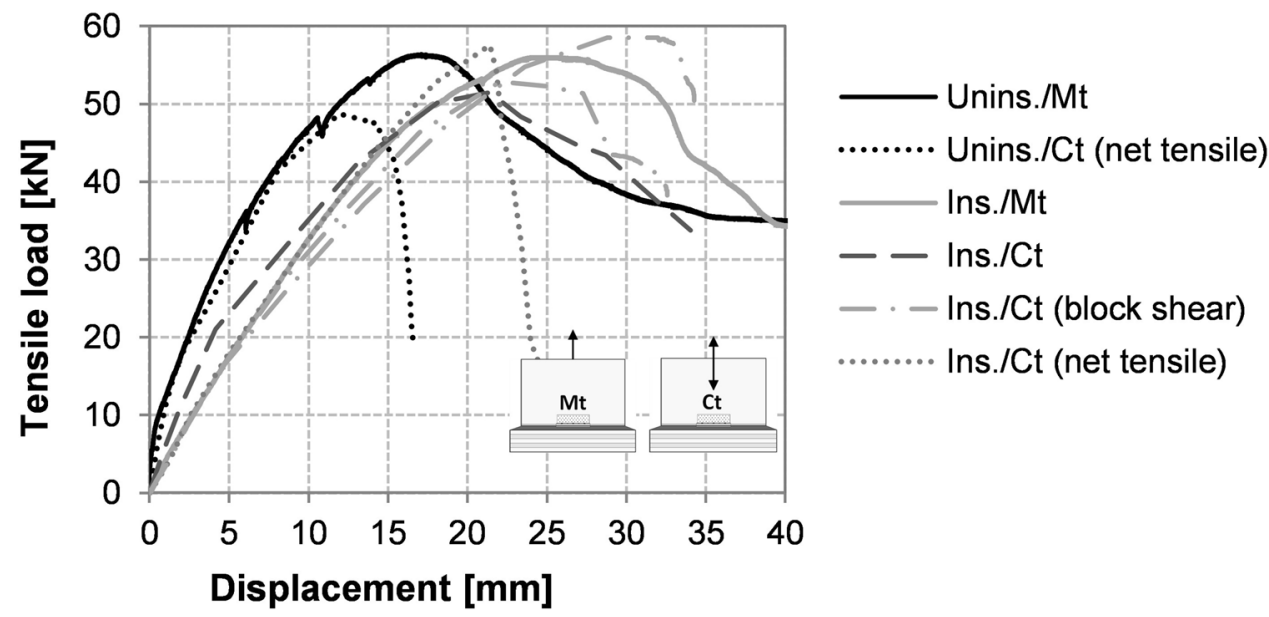

Table 4 Results of tensile loadbearing capacity, deformation capacity and stiffness obtained in monotonic and cyclic tension/ (compression) tests

\begin{tabular}{llllllllll}
\hline Test no. & Test & $\begin{array}{l}\text { Failure } \\
\text { mecha- } \\
\text { nism }\end{array}$ & $F_{\max }[\mathrm{kN}]$ & $\begin{array}{l}\Delta F_{\max , 1-3} / \\
F_{\max , 1}[/]\end{array}$ & $F_{\text {id }}[\mathrm{kN}]$ & $d_{\mathrm{u}}[\mathrm{mm}]$ & $\mu[/]$ & $K_{\text {ef }}[\mathrm{kN} / \mathrm{mm}]$ & $\begin{array}{l}K_{0.1-0.4} \\
{[\mathrm{kN} / \mathrm{mm}]}\end{array}$ \\
\hline 1 & Unins./Mt & $\mathrm{a}$ & 56.4 & & 50.2 & 26.4 & 3.47 & 6.60 & 6.18 \\
2 & Ins./Mt & $\mathrm{a}$ & 56.0 & & 52.0 & 35.0 & 2.19 & 3.25 & 3.23 \\
3 & Unins./Ct & $\mathrm{c}$ & 48.7 & $8.9 \%$ & 48.9 & 15.9 & 1.76 & 5.40 & 5.26 \\
4 & Ins./Ct & $\mathrm{b}$ & 58.5 & $24.1 \%$ & 55.3 & 34.3 & 1.75 & 2.83 & 2.78 \\
5 & Ins./Ct & $\mathrm{b} / \mathrm{c}$ & 52.8 & $9.8 \%$ & 49.0 & 32.4 & 1.98 & 3.00 & 3.17 \\
6 & Ins./Ct & $\mathrm{c} / \mathrm{b}$ & 57.6 & a & 54.3 & 22.5 & 1.33 & 3.20 & 3.17 \\
7 & Ins./Ct & $\mathrm{a}$ & 51.5 & $19.6 \%$ & 45.6 & 31.3 & 2.88 & 4.19 & 4.72 \\
\hline
\end{tabular}

$a$ withdrawal of the screws from the floor panel, $b$ block shear failure of CLT wall panel outer laminations, $c$ net tensile failure of CLT wall panel, $F_{\max }$ tensile load-bearing capacity, $\Delta F_{\max , 1-3} / F_{\max , 1}$ strength degradation in 3rd cycle compared to 1st cycle for amplitude displacements, at which maximum resistance was obtained, $F_{\text {id }}$ idealized tensile load-bearing capacity, $d_{\mathrm{u}}$ ultimate displacement (at $80 \%$ of post-peak loadbearing capacity), $\mu$ ductility, $K_{\text {ef }}$ effective stiffness (stiffness of the bi-linear curve), $K_{0.1-0.4}$ elastic stiffness (secant stiffness at 0.1 and $0.4 F_{\text {max }}$ )

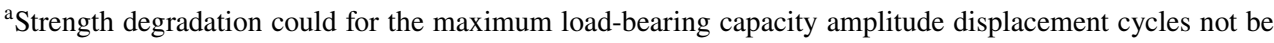
obtained due to brittle failure of the specimen in the 1st loading cycle together with its failure mode. Despite the relatively low number of tests the results indicate that the insulation has no significant influence on the tensile load-bearing capacity of the tested connection. The average $F_{\max }$ of all specimens, where the net tensile failure of the CLT crosssection did not occur, was $55.1 \mathrm{kN}(\mathrm{CoV} 4.6 \%)$. Similar maximum forces in both monotonic and cyclic tests on specimens with and without insulation were obtained. On the other hand, the changes in failure mechanism under tensile loading revealed that the capacity of the connection in the part of the CLT wall and in the part of the CLT slab are similar. Such response of the connection is not satisfactory for use in seismic areas, where the location of energy dissipation inside the connection should be predetermined and not influenced by other factors. The different failure mechanisms obtained also explain the high variation in the obtained ductilities summarized in Table 4 . Higher ductility was obtained for the specimens where the withdrawal of the screws was the critical mechanism (average $\mu$ equalled 2.85 for withdrawal (CoV 18.3\%) vs. 1.87 for block shear CLT failure (CoV 6.1\%)). The loadbearing capacity of the connection in tension is therefore largely dependent on the type of CLT cross-section (thickness and orientation of the laminations, no. of layers etc.) and the boundary conditions (distance of the angle bracket from the edge of the CLT wall). The decrease in the loadbearing capacity for the same type of connection when net tensile failure occurred can amount to $15 \%$ (in the case of the uninsulated specimens).

Another significant difference that can be obtained from the tension/compression test is the average effective stiffness in tension, which was up to $45 \%$ lower for the insulated than for the uninsulated specimens. A possible explanation for the stiffness reduction is the additional rotation of the steel bracket enabled by the insulation underneath; during tensile loading, the uplift causes a rigid rotation of the bracket 


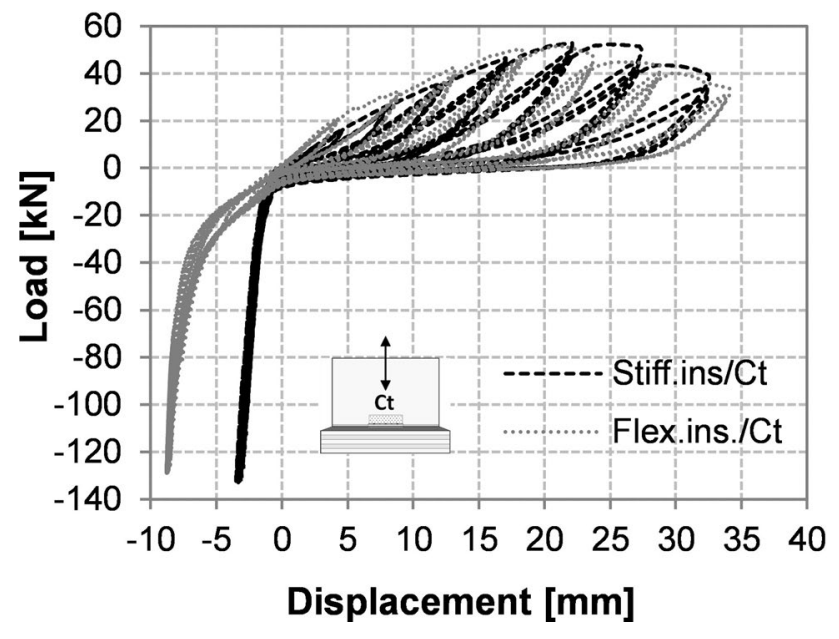

Fig. 10 Force-displacement curves for cyclic tension/compression tests $(\mathrm{Ct})$ of specimens with stiff (Stiff.ins.) and more flexible (Flex. ins.) insulation bedding

that is impeded by the screws and the floor panel for the uninsulated specimen, while for the insulated specimens, the insulation layer enables additional rotation due to the compression of the insulation.

Regarding the type of insulation, the only distinct difference in the behaviour was in the deformation of the flexible and stiff insulation under compressive loading, which can be seen in Fig. 10, where force-displacement diagrams obtained in cyclic tests of two specimens are compared.

The results show that despite the fact that the connection can withstand both shear and uplift forces, its design could be improved for its use in the seismic regions, thus to have a more controlled and predefined failure mechanism. To prevent the block shear failure under tensile loading (and even to enable higher uplift displacement in case of rocking in the structures), the height of the wall flange of the bracket could be increased as well as the end distance of the bottom row of screws. This should be done especially when insulation under the CLT walls is used, since it additionally reduces the end distance of the screws in the CLT. For the tested connection, the end distance is approximately $6 d_{\mathrm{sc}}$, which is a limit end distance for self-tapping screws in CLT side face as recommended by Ringhofer et al. (2018).

It was assumed in the experiment that the angle bracket is loaded purely in tension and compression-as a replacement of a classical hold-down. In reality, however, the intended use of such angle bracket is always in shear and tensile loading combined. The test method used here is therefore used only as an indication of the possible mechanism when the tensile load is predominant. Future investigations of different CLT wall layups and different combinations of vertical and horizontal loads are necessary. A more appropriate test method (closest to the real stress state in the connection) for obtaining the nonlinear response of the connection would be the in-plane racking tests of the CLT wall system.

\subsection{Energy dissipation and strength impairment}

Another important parameter that characterizes the performance of structural elements under seismic loading is the energy dissipation. For the conducted cyclic shear and cyclic tension/compression tests the energy dissipation was evaluated for each cycle of the force-displacement hysteresis curves. The dissipated energy of a loading cycle $E_{\text {DIS }}$ is represented by the area within one complete hysteresis loop (Fig. 11a), but since $E_{\text {DIS }}$ depends on the lateral displacement, it was evaluated relatively in comparison to the input energy $E_{\mathrm{INP}}$, defined as the work of the actuator needed to deform the connection up to the maximum amplitude displacement (the area below the part of the hysteresis loop where the absolute value of displacement is increasing, see Fig. 11a). Commonly used to evaluate the energy dissipation is the equivalent viscous damping coefficient $\xi$ (Chopra 1995), for the evaluation of which the input energy is differently defined ( $E_{\mathrm{INP}}^{*}$ in Fig. 11b). For a comparison of $E_{\mathrm{DIS}} / E_{\mathrm{INP}}$ and $\xi$ obtained in the cyclic shear tests, the results presented in Fig. 12a, b were obtained by considering both directions of loading in order to take into account the unsymmetrical performance in the two directions of loading. It should be noted that the results of $E_{\mathrm{DIS}} / E_{\mathrm{INP}}$ and $\xi$ for the cyclic tension/compression tests (in Fig. 13a, b, respectively) are shown in terms of the amplitude displacements in the
Fig. 11 a Dissipated $\mathrm{E}_{\mathrm{DIS}}$ and input energy $\mathrm{E}_{\mathrm{INP}}$ of one loading cycle; $\mathbf{b}$ dissipated $\mathrm{E}_{\mathrm{DIS}}$ and input energy $\mathrm{E}_{\mathrm{INP}} *$ of one loading cycle considered for the calculation of the equivalent damping coefficient $\xi$

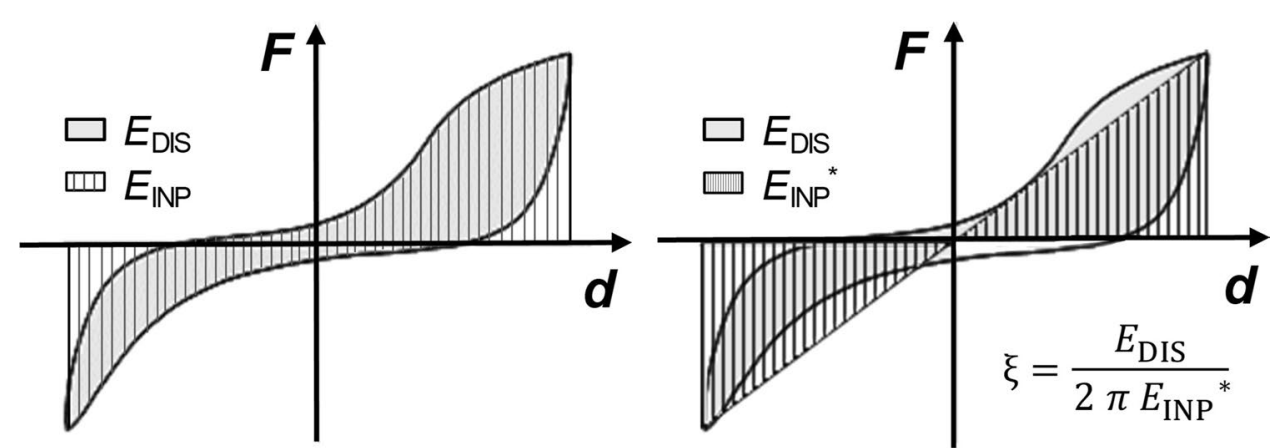



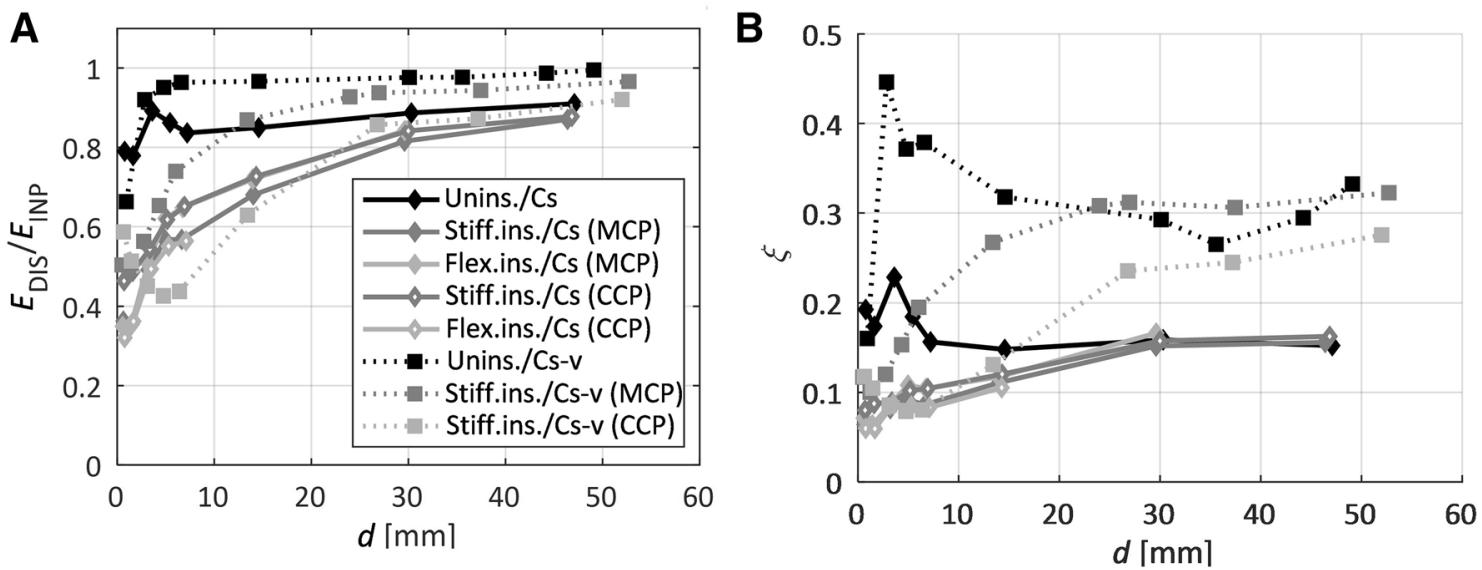

Fig. 12 a Dissipated vs. input energy ratio $\mathrm{E}_{\mathrm{DIS}} / \mathrm{E}_{\mathrm{INP}}$; $\mathbf{b}$ equivalent damping coefficient $\xi$ for the 1 st amplitude displacement loading cycles obtained in cyclic shear tests for uninsulated and insulated specimens ( $\mathrm{MCP}$ - mixed cellular polyurethane, $\mathrm{CCP}$ - closed cellular polyurethane)

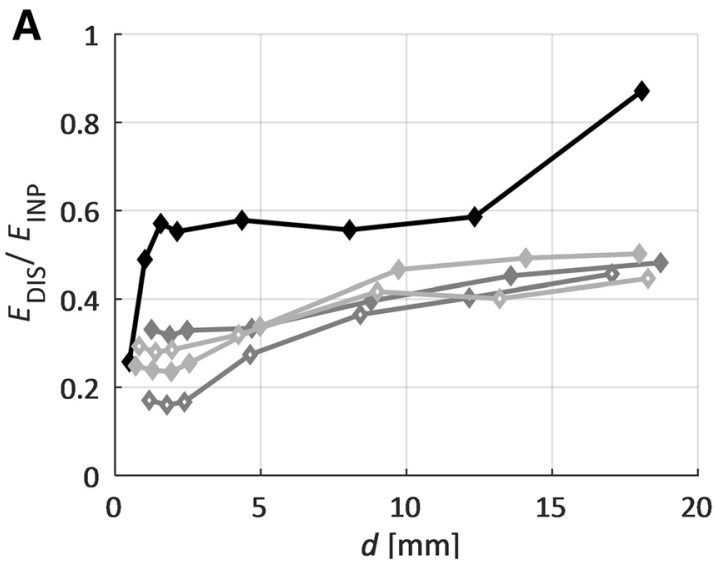

Fig. 13 a Dissipated vs. input energy ratio $\mathrm{E}_{\mathrm{DIS}} / \mathrm{E}_{\mathrm{INP}} ; \mathbf{b}$ equivalent damping coefficient $\xi$, obtained in 1st amplitude displacement loading cycles of the cyclic tension/compression tests and presented in

tensile direction of loading and that for these comparisons, the specimens are divided with regard to their elastic properties and their material structure.

The results show that the energy dissipation under shear loading was, in general, lower in the case of the insulated specimens than in the case of the uninsulated specimens. The difference was very small for larger lateral displacements, because the primary mechanism of the energy dissipation was similar for the uninsulated as well as the insulated specimens; for shear tests with no vertical load, the main dissipation occurred due to the deformation of the steel angle bracket and screws as well as the embedment and withdrawal of the screws. For smaller lateral displacements, the insulated specimens dissipated less energy than the uninsulated specimens. This can be explained by the rocking of the wall panels due to the elastic deformation of the insulation bedding, which prevented the embedment of the screws into the

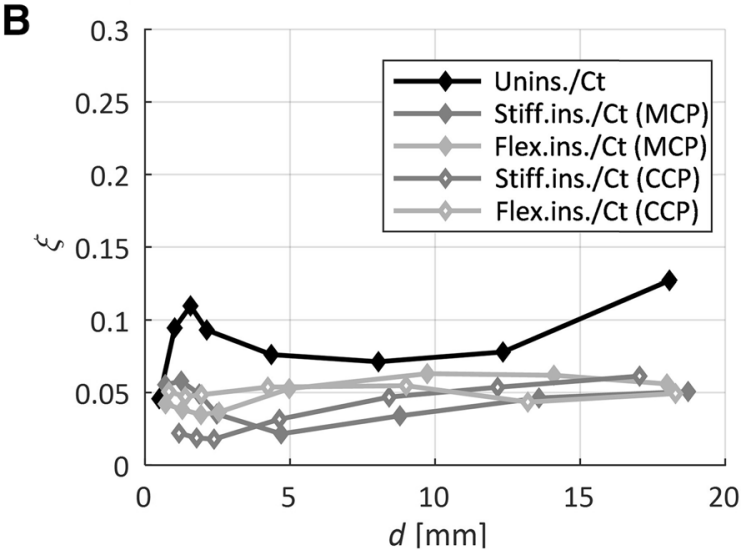

dependence of tensile displacement amplitudes for uninsulated and insulated specimens (MCP - mixed cellular polyurethane, CCP closed cellular polyurethane)

timber cross-section at smaller displacements and caused a more pronounced pinching behaviour, seen in the hysteresis curve in Fig. 4. With increasing displacement, the difference in relative energy dissipation is decreasing. The values of $\xi$ for the first amplitude displacement cycles ranged between 0.110 and 0.228 for the uninsulated specimens and between 0.050 and 0.243 for the insulated specimens. The energy dissipation was decreased with cycle repetitions and was for the third cycles similar for the uninsulated and insulated specimens. For the third amplitude displacement loading cycles, the $\xi$ values ranged between 0.073 and 0.110 for the uninsulated specimens and between 0.060 and 0.124 for the insulated specimens.

The vertical load proved to be beneficial in terms of the dissipated energy, since the additional energy was dissipated through friction. Especially for the uninsulated specimen, very high dissipation was obtained already for small lateral 
displacements. For the first amplitude displacement cycles $\xi$ ranged between 0.160 and 0.446 for uninsulated specimens and between 0.079 and 0.323 for insulated specimens. For the third cycles, $\xi$ ranged between 0.295 and 0.528 and between 0.079 and 0.452 for the uninsulated and insulated specimens, respectively. Only the results of the cyclic tests with the coupled vertical load confirm the difference in energy dissipation with regard to different cellular structure of the insulation material. Indeed, the mixed cellular structure of the elastomer provides more damping.

The energy dissipation was lower for the insulated specimens in comparison to the uninsulated specimens also under tensile and compressive loading, which can again be explained by the additional rotation of the angle bracket due to the insulation in the case of the insulated specimens. While again the difference was substantial for smaller displacements, it decreased with increasing displacements. The minimum and maximum $\xi$ for the first amplitude displacement cycles were 0.046 and 0.127 for the uninsulated specimens and 0.018 and 0.063 for the insulated specimens.

The strength impairment was evaluated for every cycle in both directions of loading. In Tables 2 and 4, the average strength degradations $\Delta F_{\text {max }, 1-3} / F_{\max , 1}$ obtained in amplitude displacement cycles, at which maximum load-bearing capacities were achieved, are presented for shear and tensile tests, respectively. They are calculated as the difference of maximum resistance in the 1st and in the 3rd loading cycle, relative to the maximum resistance obtained (in the 1st loading cycle). For the shear tests, $\Delta F_{\max , 1-3} / F_{\max , 1}$ was evaluated separately for each direction of loading (not necessarily at the same amplitude displacements) and average results of average $\Delta F_{\max , 1-3} / F_{\max , 1}$ for the two directions of loading are presented for insulated and uninsulated specimens. For the tensile tests, strength degradation at maximum resistance loading cycles is presented only for the tensile part of the loading. In terms of strength degradation, insulation proves beneficial since it evidently reduced the strength degradation for repeated loading at the amplitude displacements at which the maximum resistance was obtained. Also at lower amplitude displacements, average strength degradation was smaller for insulated than for uninsulated specimens; for pure shear $(8.3 \%$ vs. $11.5 \%)$ as well as for coupled shear and vertical loading ( $4.1 \%$ vs. $5.8 \%)$ and tensile loading $(6.1 \%$ vs. $11.6 \%)$.

\section{Conclusion}

From the results of the experimental campaign the following conclusions can be drawn:

1. The damage mechanism of the CLT panels connected with the (insulated) steel angle bracket exhibited ductile behaviour under shear loading. Besides the deformations of the screws and the angle bracket, the damage mechanisms were the embedment and withdrawal of the screws from the timber, mainly in the wall panel.

2. For tensile loading, the capacity of the connection in the part of the CLT wall and in the part of the CLT slab proved to be similar; different failure mechanisms occurred (withdrawal of the screws from the floor panel, embedment of the screws to the wall panel and in some cases block shear failure of the CLT wall panel), while the coefficient of variation for the connections' loadbearing capacity was low. The behaviour of the connection under uplift forces could be improved for its use in seismic regions to have a more controlled failure mechanism in the predefined part of the connection. Brittle block shear failure of the CLT should by all means be avoided. For this, the flange of the angle bracket on the CLT wall could be increased together with end distance of the screws.

3. The obtained load-bearing capacities confirm that the connection is, besides the shear forces, able to withstand significant uplift forces due to the inclined self-tapping screws in the floor panel and can therefore also be considered as a hold down. However, a reduction in the load-bearing capacity is expected in case of shear-uplift interaction (Liu and Lam 2018). A compressive load in combination with shear loading increases the shear load-bearing capacity due to the resistance provided by the friction between the CLT elements. Since in reality, with regard to disposition of the connectors both shear-uplift and shear-compression coupling effects are present in the connections when a CLT wall panel is subjected to in-plane shear loading, the coupling effect on the entire wall panel anchoring system should be investigated through experimental tests of full size panels and included in the numerical parametric studies.

4. The insulation bedding under the bracket and in between the CLT panels was shown not to significantly influence the load-bearing and the displacement capacity of the system, neither under shear nor under tensile/compressive loading.

5. The insulation reduced the stiffness characteristics of the system. While an average reduction of $22 \%$ of the effective stiffness was obtained for pure shear loading, a $45 \%$ reduction was obtained for the tensile loading. For pure shear loading, the difference in stiffness was the highest for small lateral displacements and should therefore by all means be considered for the analysis/design of the CLT structural system.

6. With the presence of the vertical load, a substantial stiffness increase at shear loading was obtained due to the frictional forces and also other effects (e.g. compression of the CLT slab) for both the insulated and uninsulated 
specimens. The increase was, however, higher for the uninsulated specimen, since for the insulated specimens the deformations of the insulation were present and enabled additional rocking behaviour of the specimen.

7. The relative energy dissipation and equivalent viscous damping coefficient were, in general, lower for the insulated specimens than for the uninsulated specimens, since the additional deformations of the insulation caused change of hysteresis curve with more pronounced pinching. The difference in the energy dissipation between them, however, decreased with increasing displacements and repeated cycles of loading and no major differences are therefore expected in the case of a severe seismic loading. The applied vertical load at cyclic shear loading proved to be beneficial also in terms of dissipated energy, since additional energy was dissipated through friction. In shear tests, the insulation also reduced the strength degradation with repeating loading cycles.

The obtained response of the small-scale, single, insulated, steel angle bracket connection under pure shear loading, tensile/compressive loading as well as coupled shear and vertical loading could serve as a basis for the prediction of the response of CLT panels connected with the developed insulated angle bracket connections instead of traditional hold downs and angle brackets. However, to confirm the results and have an even more in-depth understanding of the behaviour of the structural system, an experimental study with tests on full-scale CLT panels connected with multiple steel angle brackets under different boundary conditions should be conducted and evaluated.

Acknowledgements The authors gratefully acknowledge the financial support of the European Commission for the project InnoRenew CoE (Grant Agreement \#739574) under the Horizon2020 WidespreadTeaming program, as well as that of the Slovenian Research Agency (Research Core Funding No. (P2-0273)). Companies Getzner, Pitzl, XLam Dolomiti and Lespatex are also gratefully acknowledged for providing material for the testing.

\section{Compliance with ethical standards}

Conflict of interest The authors declare that they have no conflict of interest.

Ethical approval The authors declare that there is no issue concerning ethical standards.

Informed consent Informed consent was obtained from all individual participants included in the study.

Open Access This article is licensed under a Creative Commons Attribution 4.0 International License, which permits use, sharing, adaptation, distribution and reproduction in any medium or format, as long as you give appropriate credit to the original author(s) and the source, provide a link to the Creative Commons licence, and indicate if changes were made. The images or other third party material in this article are included in the article's Creative Commons licence, unless indicated otherwise in a credit line to the material. If material is not included in the article's Creative Commons licence and your intended use is not permitted by statutory regulation or exceeds the permitted use, you will need to obtain permission directly from the copyright holder. To view a copy of this licence, visit http://creativecommons.org/licenses/by/4.0/.

\section{References}

Benedetti F, Rosales V, Opazo-Vega A et al (2019) Experimental and numerical evaluation of hold-down connections on radiata pine Cross-Laminated-Timber shear walls: a case study in Chile. Eur J Wood Prod 77:79-92. https://doi.org/10.1007/s00107-018-1365-1

Brandner R, Flatscher G, Ringhofer A et al (2016) Cross laminated timber (CLT): overview and development. Eur J Wood Prod 74:331-351. https://doi.org/10.1007/s00107-015-0999-5

Caniato M, Bettarello F, Fausti P et al (2017) Impact sound of timber floors in sustainable buildings. Build Environ 120:110-122. https ://doi.org/10.1016/j.buildenv.2017.05.015

Chopra AK (1995) Dynamics of structures: theory and applications to earthquake engineering. Prentice Hall, Englewood Cliffs

D’Arenzo G, Rinaldin G, Fossetti M et al (2018) Tensile and shear behaviour of an innovative angle bracket for CLT structures. In: Proceedings WCTE 2018. Seoul, South Korea

D’Arenzo G, Rinaldin G, Fossetti M, Fragiacomo M (2019) An innovative shear-tension angle bracket for Cross-Laminated Timber structures: experimental tests and numerical modelling. Eng Struct 197:109434. https://doi.org/10.1016/j.engstruct.2019.109434

Dias AMPG, Cruz HMP, Lopes SMR, van de Kuilen JW (2010) Stiffness of dowel-type fasteners in timber-concrete joints. Proc Inst Civ Eng Struct Build 163:257-266. https://doi.org/10.1680/ stbu.2010.163.4.257

DIBt (2017) ETA-12/0276, WBS—wood building screws und CPSchipboard screws. Deutsche Institut für Bautechnik, (DIBt)

Dujić B, Pucelj J, Žarnić R (2004) Testing of racking behavior of massive wooden wall panels. In: 37th CIB-W18 Meeting, Edinburgh, Scotland. Paper 37-15-2

Dujić B, Aicher S, Žarnić R (2006) Testing of wooden wall panels applying realistic boundary conditions. In: Proceedings of the 9th World Conference On Timber Engineering. Oregon State University Conference Services, Portland, Oregon, USA, pp $1186-1193$

EN 12512:2005 (2005) Timber structures-test methods-cyclic testing of joints made with mechanical fasteners. European Committee for Standardization, (CEN)

Flatscher G, Bratulic K, Schickhofer G (2015) Experimental tests on cross-laminated timber joints and walls. Proc Inst Civ Eng Struct Build 168:868-877. https://doi.org/10.1680/stbu.13.00085

Follesa M, Fragiacomo M, Casagrande D et al (2018) The new provisions for the seismic design of timber buildings in Europe. Eng Struct 168:736-747. https://doi.org/10.1016/j.engst ruct.2018.04.090

Foster RM, Reynolds TPS, Ramage MH (2016) Proposal for Defining a Tall Timber Building. J Struct Eng 142:02516001. https://doi. org/10.1061/(ASCE)ST.1943-541X.0001615

Fragiacomo M, Dujić B, Šušteršič I (2011) Elastic and ductile design of multi-storey crosslam massive wooden buildings under seismic actions. Eng Struct 33:3043-3053. https://doi.org/10.1016/j.engst ruct.2011.05.020

Gavrić I, Fragiacomo M, Ceccotti A (2015a) Cyclic behavior of CLT wall systems: experimental tests and analytical prediction models. 
J Struct Eng 141:04015034. https://doi.org/10.1061/(ASCE) ST.1943-541X.0001246

Gavrić I, Fragiacomo M, Ceccotti A (2015b) Cyclic behaviour of typical metal connectors for cross-laminated (CLT) structures. Mater Struct 48:1841-1857. https://doi.org/10.1617/s11527-014-0278-7

Gelfi P, Giuriani E, Marini A (2002) Stud shear connection design for composite concrete slab and wood beams. J Struct Eng 128:1544-1550. https://doi.org/10.1061/ (ASCE)0733-9445(2002)128:12(1544)

Getzner GmbH (2019a) Sylomer: material properties and vibration isolation technical information. https://www.getzner.com/en/downl oads. Accessed 1 Feb 2019

Getzner GmbH (2019b) Sylodyn: material properties and vibration isolation technical information. https://www.getzner.com/en/downl oads. Accessed 1 Feb 2019

Hummel J, Flatscher G, Seim W, Schickhofer G (2013) CLT wall elements under cyclic loading-details for anchorage and connection. COST Action FP1004 152-165

ISO 16670:2003 (2003) Timber structures-joints made with mechanical fasteners-quasi-static reversed-cyclic test method. International Organization for Standardization, (ISO)

Izzi M, Casagrande D, Bezzi S et al (2018) Seismic behaviour of crosslaminated timber structures: a state-of-the-art review. Eng Struct 170:42-52. https://doi.org/10.1016/j.engstruct.2018.05.060

Kobayashi K, Yasumura M (2011) Evaluation of plywood sheathed shear walls with screwed joints tested according to ISO 21581. In: Proceedings of CIB-W18 meeting. KIT, Alghero, Italy, p 10, Paper 44-15-8

Lauriola MP, Sandhaas C (2006) Quasi-static and pseudo-dynamic tests on XLAM walls and buildings. In: Proceedings of the Cost E29 international workshop on earthquake engineering on timber structures. Coimbra, Portugal, pp 119-133

Liu J, Lam F (2018) Experimental test of coupling effect on CLT angle bracket connections. Eng Struct 171:862-873. https://doi. org/10.1016/j.engstruct.2018.05.013

Liu J, Lam F (2019) Experimental test of coupling effect on CLT hold-down connections. Eng Struct 178:586-602. https://doi. org/10.1016/j.engstruct.2018.10.063

Liu J, Lam F, Foschi RO, Li M (2020) Modeling the coupling effect of CLT connections under biaxial loading. J Struct Eng 146:04020040. https://doi.org/10.1061/(ASCE)ST.1943$541 X .0002589$

OIB (2017) ETA-12/0347: X-LAM DOLOMITI-CLT. Österreichisches Institut für Bautechnik, (OIB)

Okabe M, Yasumura M, Kobayashi K et al (2012) Effect of vertical load under cyclic lateral load test for evaluating Sugi CLT wall panel. Auckland, New Zealand, pp 89-96

Pei S, van de Lindt JW, Popovski M et al (2016) Cross-laminated timber for seismic regions: progress and challenges for research and implementation. J Struct Eng 142:E2514001. https://doi. org/10.1061/(ASCE)ST.1943-541X.0001192

Pitzl, Getzner (2018) GePi connectors: Powerful soundproofing angle brackets. https://www.pitzl-connectors.com/gepi/. Accessed 1 Feb 2019

Popovski M, Schneider J, Schweinsteiger M (2010) Lateral load resistance of cross-laminated wood panels. In: Proceedings of the 11th world conference on timber engineering. Trees and Timber Institute, National Research Council, Trentino, Italy, pp 3394-3403

Pozza L, Saetta A, Savoia M, Talledo D (2017) Coupled axial-shear numerical model for CLT connections. Constr Build Mater 150:568-582. https://doi.org/10.1016/j.conbuildmat.2017.05.141

Pozza L, Ferracuti B, Massari M, Savoia M (2018) Axial-shear interaction on CLT hold-down connections-experimental investigation. Eng Struct 160:95-110. https://doi.org/10.1016/j.engst ruct.2018.01.021

Ramage MH, Burridge H, Busse-Wicher M et al (2017) The wood from the trees: the use of timber in construction. Renew Sustain Energy Rev 68:333-359. https://doi.org/10.1016/j.rser.2016.09.107

Reichelt H, Gerhaher U, Wiederin S, Maderebner R (2016) Characteristics of acoustic layers for structural design of timber constructions. In: Proceedings of the WCTE 2016 world conference on timber engineering. TUVerlag, Vienna, Austria, pp 2904-2911

Reynolds T, Casagrande D, Tomasi R (2016) Comparison of multi-storey cross-laminated timber and timber frame buildings by in situ modal analysis. Constr Build Mater 102:1009-1017. https://doi. org/10.1016/j.conbuildmat.2015.09.056

Ringhofer A, Brandner R, Blaß HJ (2018) Cross laminated timber (CLT): design approaches for dowel-type fasteners and connections. Eng Struct 171:849-861. https://doi.org/10.1016/j.engst ruct.2018.05.032

Säly L, Burtscher P, Grass B (2008) Angle connector. European patent EP 2022902 B1

Schneider J, Karacabeyli E, Popovski M et al (2014) Damage assessment of connections used in cross-laminated timber subject to cyclic loads. J Perform Constr Facil 28:A4014008. https://doi. org/10.1061/(ASCE)CF.1943-5509.0000528

Tomasi R, Sartori T (2013) Mechanical behaviour of connections between wood framed shear walls and foundations under monotonic and cyclic load. Constr Build Mater 44:682-690. https://doi. org/10.1016/j.conbuildmat.2013.02.055

Yasumura M, Kawai N (1998) Estimating seismic performance of wood-framed structures. In: Proceedings of the 5th world conf. on timber engineering (WCTE). Montreaux, Switzerland, pp $564-571$

Publisher's Note Springer Nature remains neutral with regard to jurisdictional claims in published maps and institutional affiliations. 